\title{
Diagnosis and management of congenital hyperinsulinism: a case report
}

\author{
Boudewijn Bakker and Wilma Oostdijk \\ Department of Paediatrics, Leiden University Medical Centre, PO Box 9600, 2300 RC Leiden, The Netherlands \\ (Correspondence should be addressed to B Bakker; Email: b.bakker@lumc.nl)
}

\section{Introduction}

Congenital hyperinsulinism (CHI) is a common cause of persistent hypoglycaemia in neonates, with an estimated incidence of one in 50000 live births (1). The molecular basis for $\mathrm{CHI}$ can be established in approximately $50 \%$ of the cases and is categorised as channelopathies - defects in the ATP-sensitive potassium $\left(\mathrm{K}_{\mathrm{ATP}}\right)$ channels that regulate insulin secretion, and metabolopathies - defects in metabolic pathways altering $\beta$-cell function (2). Channelopathies form the largest group and can be further sub-divided into focal and diffuse forms. In contrast to metabolopathies, most channelopathies do not respond to pharmacological treatment and require surgical removal of either focal lesions or, in diffuse forms, near total $(>97 \%)$ pancreatectomy. This case report describes the diagnostic and therapeutic challenges in a patient with CHI. More extensive background information on $\mathrm{CHI}$ can be found elsewhere (2).

\section{Case report}

A girl born large for gestational age (birth weight $>+2.5$ SDS) after an uneventful pregnancy, presented $1 \mathrm{~h}$ after birth with apnoea and convulsions, caused by severe hypoglycaemia (serum glucose $<0.6 \mathrm{mmol} / \mathrm{l}$ ). Hypoglycaemia was treated with $5 \mathrm{ml} / \mathrm{kg} 10 \%$ glucose i.v. followed by a continuous i.v. glucose infusion. Laboratory investigations at the time of hypoglycaemia (Table 1) showed hyperinsulinaemic, hypoketotic, hypofattyacidaemic hypoglycaemia, and a glucose infusion rate of $19 \mathrm{mg} / \mathrm{kg}$ per min was required to maintain serum glucose above $3 \mathrm{mmol} / \mathrm{l}$. A diagnosis of 'hyperinsulinism' was made. Maternal gestational diabetes was excluded by an oral glucose tolerance test, and at the end of the first week the patient was transferred to our hospital for further assessment and treatment.

She had no dysmorphic features suggestive of a syndromic cause for CHI. Treatment was started with diazoxide (15 mg/kg per day in three doses) and

This paper was presented at the 4th Ferring Pharmaceuticals International Paediatric Endocrinology Symposium, Paris (2006). Ferring Pharmaceuticals has supported the publication of these proceedings. hydrochlorothiazide ( $7 \mathrm{mg} / \mathrm{kg}$ per day in two doses), which resulted in a $25 \%$ decrease in glucose requirement. Higher doses of diazoxide were not tolerated, so a continuous i.v. infusion of octreotide $15 \mu \mathrm{g} / \mathrm{kg}$ per day was added, which produced a modest effect on glucose requirement. Increasing the octreotide dose was ineffective and glucagon $5 \mu \mathrm{g} / \mathrm{kg}$ per h i.v. was needed to normalise glucose intake.

The poor response to diazoxide and the results of additional investigations (Table 1) indicated a channelopathy as the most likely cause of $\mathrm{CHI}$. Analysis of the ABCC 8 and KCNJ11 genes (encoding for the SUR1 and Kir6.2 proteins of the $\mathrm{K}_{\mathrm{ATP}}$ channel respectively) was undertaken. As the mother was from central Finland and the father had Finnish ancestors, initial screening focussed on the Finnish founder valine 187 aspartic acid substitution in the SUR1 protein (3).

The patient was transferred to another centre for $\left[{ }^{18} \mathrm{~F}\right]$ fluoro-L-DOPA positron emission tomography (PET), in order to differentiate between focal and diffuse $\mathrm{CHI}$. It was requested that medication need not be discontinued and carbidopa was given before the PET. No pancreatic uptake of $\left[{ }^{18} \mathrm{~F}\right]$ fluoro-L-DOPA was observed; the patient was therefore transferred to a third centre for diagnostic laparoscopy with pancreatic biopsies. No focal lesions could be identified and a large biopsy (approximately 50\% of the pancreas) was taken. Immunohistochemistry of the pancreatic biopsy showed diffuse intense staining for insulin and pro-insulin compatible with a diffuse form of CHI. Mutation analysis revealed a maternally derived V187D substitution. The result excludes the focal form of CHI, which results from a paternally derived mutation in SUR1 combined with a loss of maternally derived unaffected allele in the hyperplastic islets (4).

Diazoxide and hydrochlorothiazide were restarted after surgery and the patient remained normoglycaemic with a glucose intake of $7.5 \mathrm{mg} / \mathrm{kg}$ per min. Most patients with a channelopathy do not respond to diazoxide, but several attempts at stopping diazoxide resulted in an increase in glucose requirement. No hypoglycaemic events occurred over the next 4 weeks, including monitoring glucose levels continuously during $96 \mathrm{~h}$ using a continuous glucose monitoring system (Medtronic Minimed, Inc., Northridge, CA, USA).

The patient was, however, readmitted 3 weeks after discharge for recurrent hypoglycaemia. Each therapeutic 
Table 1 Results of laboratory investigations at the time of hypoglycaemia.

\begin{tabular}{|c|c|c|}
\hline Analyte & Result & $\begin{array}{l}\text { Response to } \\
\text { hypoglycaemia }\end{array}$ \\
\hline Glucose & $1.8 \mathrm{mmol} / \mathrm{l}$ & \\
\hline Growth hormone & $98.3 \mathrm{mU} / \mathrm{l}$ & Adequate \\
\hline Cortisol & $1950 \mathrm{nmol} / \mathrm{l}$ & Adequate \\
\hline Insulin & $12 \mathrm{mU} / \mathrm{l}$ & Inadequate suppression \\
\hline C-peptide & $0.62 \mathrm{nmol} / \mathrm{l}$ & Inadequate suppression \\
\hline$\beta$-OH-butyrate & $0.35 \mathrm{mmol} / \mathrm{l}$ & Inadequate ketogenesis \\
\hline Total free fatty acids & $1078 \mu \mathrm{mol} / \mathrm{l}$ & Limited lipolysis \\
\hline Urine ketone bodies & Absent & Inadequate ketogenesis \\
\hline Ammonia & $44 \mu \mathrm{mol} / \mathrm{l}$ & \\
\hline Acyl-carnitine profile & Normal & - \\
\hline $\begin{array}{l}\text { Transferrin iso-electric } \\
\text { focussing }\end{array}$ & Normal & - \\
\hline
\end{tabular}

intervention to reduce insulin secretion had only a temporary effect. Six weeks later, glucose intake was still $11 \mathrm{mg} / \mathrm{kg}$ per min with starch-enriched formula, administered by a 3-hourly feeding schedule and continuous nocturnal feeding via a gastrostomy tube. Maximum tolerable doses of diazoxide $16 \mathrm{mg} / \mathrm{kg}$ per day, hydrochlorothiazide $8 \mathrm{mg} / \mathrm{kg}$ per day and octreotide $25 \mu \mathrm{g} / \mathrm{kg}$ per day continuously s.c were needed. Consequently, laparoscopic near total pancreatectomy was performed, leaving only a small slip of pancreatic tissue remaining beneath the distal end of the common bile duct. During surgery, ectopic pancreatic tissue was removed from the duodenal wall.

Within a week, diabetes mellitus had developed and required insulin therapy. However, the patient became hyperinsulinaemic again and medical treatment for hyperinsulinism was reinstated. As maximal therapy did not prevent hypoglycaemia completely, she was transferred to a specialised centre abroad for a third pancreatectomy. Hypoglycaemia did not recur during this period and after 1 month of being euglycaemic, she was discharged.

The paternally derived SUR1 mutation was subsequently identified (splice site mutation intron 10:c. $1630+1 \mathrm{G}>\mathrm{T}$ ). Over the next 6 months, hypoglycaemia (glucose $<2.6 \mathrm{mmol} / \mathrm{l}$ ) occurred less than once a month and at the age of 1 year, psychomotor development was completely normal. She was admitted for an episode of gastroenteritis at 13 months of age. Diazoxide treatment was also stopped. Continuous s.c. octreotide was successfully replaced by lanreotide $60 \mathrm{mg}$ s.c. every 4 weeks by 18 months of age. Her height develops along the +12.0 SDS line (target height +0.9 SDS) and weight for height between +1.5 and +2.0 SDS.

\section{Discussion}

Channelopathies are the most common and severe forms of CHI. Early diagnosis and treatment are mandatory to prevent recurrent neuroglycopenia, which results in neurological damage in over $20 \%$ of patients with $\mathrm{CHI}(5)$.

Unresponsiveness to high doses of diazoxide in this case suggested a channelopathy, and thus an attempt was made to differentiate between focal and diffuse CHI using PET. The negative result of the PET is attributed to the continuation of medication and the administration of carbidopa, both having an effect on reducing $\beta$-cell activity. A recent protocol for $\left[{ }^{18} \mathrm{~F}\right]$ fluoro-L-DOPA PET states that "medication (e.g. diazoxide, octreotide and glucagon) should be discontinued for at least 2 days, and use of Carbidopa is not recommended" (6). A focal form of CHI was subsequently excluded by laparoscopy and biopsy as well as by the presence of a maternally derived pathogenic SUR1 mutation.

Therapeutic laparoscopic pancreatectomy in this case did not result in long-term adequate reduction in insulin-secretion rate. A possible explanation is that the laparoscopic approach is not optimal for near-total pancreatectomy, as in many cases the reduction in pancreatic tissue is insufficient (K Hussain, personal communication). Alternative explanations are the presence of ectopic pancreatic tissue (e.g. in the duodenal wall) or regeneration of the pancreas.

Recurrence of hyperinsulinism despite near-total pancreatectomy required a combination of diazoxide, hydrochlorothiazide and continuous s.c. administration of octreotide to achieve adequate control of insulin secretion. There is evidence that the natural history of $\mathrm{CHI}$ is a slow, progressive loss of $\beta$-cell function (7), and so parents prefer long-term medical treatment with somatostatin analogues rather than a further pancreatectomy. Nevertheless, if significant side effects of somatostatin analogues, such as cholelithiasis, hepatitis and growth hormone deficiency, occur in due course our patient will need to have another pancreatectomy.

\section{Conclusions}

- Differentiation between focal and diffuse forms of CHI can be achieved by $\left[{ }^{18} \mathrm{~F}\right]$ fluoro-L-DOPA PET or by laparoscopy with pancreatic biopsies. In addition, a maternally derived pathogenic mutation in SUR1 or Kir6. 2 excludes focal CHI.

- There is insufficient evidence to support the laparoscopic approach for therapeutic pancreatectomy in diffuse forms of CHI.

- Somatostatin analogues, such as octreotide and lanreotide, can be used as long-term treatment in patients with persistent hyperinsulinism despite therapeutic pancreatectomy.

- Management of CHI requires medical intensive care, modern imaging and surgical expertise combined in designated specialist centres. 


\section{References}

1 de Lonlay P, Touati G, Robert JJ \& Saudubray JM. Persistent hyperinsulinaemic hypoglycaemia. Seminars in Neonatology 20027 95-100.

2 Dunne MJ, Cosgrove KE, Shepherd RM, Aynsley-Green A \& Lindley KJ. Hyperinsulinism in infancy: from basic science to clinical disease. Physiological Reviews 200484 239-275.

3 Otonkoski T, Ammala C, Huopio H, Cote GJ, Chapman J, Cosgrove K, Ashfield R, Huang E, Komulainen J, Ashcroft FM, Dunne MJ, Kere J \& Thomas PM. A point mutation inactivating the sulfonylurea receptor causes the severe form of persistent hyperinsulinemic hypoglycemia of infancy in Finland. Diabetes 1999 48 408-415.

4 de Lonlay P, Fournet JC, Rahier J, Gross-Morand MS, Poggi-Travert F, Foussier V, Bonnefont JP, Brusset MC, Brunelle F, Robert JJ, Nihoul-Fekete C, Saudubray JM \& Junien C. Somatic deletion of the imprinted $11 \mathrm{p} 15$ region in sporadic persistent hyperinsulinemic hypoglycemia of infancy is specific of focal adenomatous hyperplasia and endorses partial pancreatectomy. Journal of Clinical Investigation 1997100 802-807.
5 Menni F, de Lonlay P, Sevin C, Touati G, Peigne C, Barbier V, Nihoul-Fekete C, Saudubray JM \& Robert JJ. Neurologic outcomes of 90 neonates and infants with persistent hyperinsulinemic hypoglycemia. Pediatrics 2001107 476-479.

6 Mohnike K, Blankenstein O, Christesen HT, De Lonlay J, Hussain K, Koopmans KP, Minn H, Mohnike W, Mutair A, Otonkoski T, Rahier J, Ribeiro M, Schoenle E \& Fekete CN. Proposal for a standardized protocol for F-DOPA-PET (PET/CT) in congenital hyperinsulinism. Hormone Research 200666 40-42.

7 Kassem SA, Ariel I, Thornton PS, Scheimberg I \& Glaser B. $\beta$-cell proliferation and apoptosis in the developing normal human pancreas and in hyperinsulinism of infancy. Diabetes 200049 1325-1333.

Received 26 June 2006

Accepted 27 July 2006 